\title{
Matsuyama University’s Statistical Studies (Using Annual Paid Vacation Research as the Basis for Student Development) Through the Use of a Student's Graduation Thesis Results ${ }^{*}$
}

\author{
Go Igusa \\ Correspondence: Go Igusa, School of Economics, Matsuyama University, Bunkyocho 4-2, Matsuyama, Ehime, Japan.
}

Received: May 17, 2018

doi:10.11114/jets.v6i8.3276
Online Published: July 19, 2018

URL: https://doi.org/10.11114/jets.v6i8.3276

\begin{abstract}
This publication seeks to consider statistics education in Japan while referencing a student paper. The paper to be considered is as follows: "Gakusei no Koudou ga Gakusei Seikatsu Manzokudo ni Ataeru Eikyou" (The Influence of Student Behavior on the Degree of Satisfaction Perceived in Student Life).

Keywords: annual paid vacation research, matsuyama university's statistical education, the reason to use statistic

\section{Introduction}

I left Tokyo 3 years ago, and moved to Matsuyama University's economics department. In this article I want to talk about the difficulty surrounding the study of statistics and how to learn statistics from the university's liberal art departments' perspective. My analysis is mostly based on what I have experienced in seminars. I focus on the problems that are connected to the entry level statistical studies (introduction to statistical studies), which are used in liberal art private universities that push out more graduates into society than typical universities.
\end{abstract}

\section{The Reason to Use Statistics}

Statistics is a tool that can be used to analyze various real world problems. When studying statistics, the most important prerequisite is to have something that you want to emphasize or some kind of thought that you want to verify. The problem with this tool is the obstacle that you run into while studying statistics. Namely, not having something you want to emphasize or a thought to verify - essentially, not having a motive or a need to analyze statistical data. Almost all of the students in private university's liberal arts, where statistics aren't studied through numbers, lack the feeling of wanting to learn something through the need to analyze objects that they are interested in, using statistical methods.

Again, on the matter of describing results of statistical analysis, there is a need to correctly describe the sequence of data. On this matter, by assigning careful reading relating to research results published during this year's holidays (doctoral dissertations, books etc.), and further, by passing on the format of past papers to students, and getting them to mimic it, students can go on to create their own original research papers according to their own interests. I also spare students the unnecessary toil of remembering the methods for recording statistical results, firstly by providing an environment that allows students to master statistics fairly well through its use.

The development of statistics has always happened through having a problem and then trying to analyze it with the use of statistics. However, currently most university students don't have a problem that they would want to analyze. In other words, if we exclude a small part of problem oriented students, then generally speaking, students don't feel the need to pursue the study of statistics.

For that reason, I have students take part in a competition in the seminar. I hold these competitions in our university with the idea of promoting research activity, so the students have a chance to report their everyday research results. The students are split up into 7 or 8 teams, with each team having their own assignment, and the goal of the competition is to have them advance their research. By having them present their material half forcefully, the students will have to think on what they want to emphasize or what topic they want to do research on.

\footnotetext{
*It should be noted that the present study is a part of the research results by the Matsuyama University special research grant received for the 2016 fiscal year.
} 


\section{Gathering Current Data}

As mentioned before, statistics is a tool to study various real world problems, but it has one huge obstacle. That being, "How do I gather statistical data?" In order to carry out statistical research, one needs to know the fundamental knowledge, memorize the types of numerical data used in statistics and how to use them, and then gather data on the interested subject. This is where most lose their motivation.

I use SSJDA (Social Science Japan Data Archive). The data archive is an institution that collects and preserves statistical research and social research data, and they provide the source data for educational purposes. Almost all of the data is managed in a way to allow it to be used for statistical analysis. Students can easily access it and with very little effort they will be able to analyze real world problems, which will also increase their motivation to study statistics.

These days, there is a lot of useful statistical software available, and with a bit of know-how the results will follow. The teachers just need to motivate the students, clear the obstacles, and the results will come if they make use of the software. Wouldn't this be a great way to start studying statistics?

Below we have an article written by a student, who is presenting their findings. It is pretty well written compared to the average university student's article, wouldn't you agree?

Acknowledgments : The data for this secondary analysis, Awareness survey on university students, Meiji Yasuda Institute of Life and Wellness, was provided by the Social Science Japan Data Archive, Center for Social Research and Data Archives, Institute of Social Science, The University of Tokyo.

\section{A Student's Article: The Influence of Student Behavior on the Degree of Satisfaction Perceived in Student Life - Hoshitaro Uchida wrote}

According to the Ministry of Education, Culture, Sports, Science and Technology's "University student life improvement policy report" (2000) the current student situation is that they are not leading a satisfactory student life, because of concerns of feeling less attached to people during a free and prosperous era. This is because there are only a few students who hold a clear vision of their future profession or what subjects they would like to study, and it is believed that the number of students, who enter university to do some soul searching, is increasing. As the employment and education options for the future broaden, there is a tendency for the students' concerns to amplify.

In addition, the rate of students continuing studies in university has greatly improved in recent years, and with the increased number of university students, the rate of university students leaving university unfinished has also increased. In fact, Yomiuri Shimbun's study on "University's ability and their efforts towards improving their education quality" (2008) revealed that from 2008 to 2010 the average rate of students leaving university unfinished during the 4 year study program was between $7.7 \%$ to $8.2 \%$ and they also noted that the rate was slightly increasing. Also, Asahi Shimbun and Kawai Juku's joint study "On the results of the 2015 Japanese university analysis" (2015) revealed the latest data on the rate of students leaving university unfinished. According to that study, the overall rate is $7.8 \%$ and it had slightly decreased from $8.1 \%$, which was the result during 2014 when the study was conducted. However, in private universities the rate is around $10 \%$, which is still high compared to public universities. Students leaving universities is not only connected to positive and voluntary reasons, such as going to study abroad or changing universities, but also negative and involuntary reasons, such as financial problems and losing the desire to study (Anegawa 2014). Apart from that, the Osaka University of Economics Essay Collection vol 64 no 1 (Hajime Shimizu 2013) says that from a financial point of view, the rate of students leaving university is connected to the students level of satisfaction. The students feel that universities are not providing satisfactory classes or suitable services that would be worth their financial and time investment, and thus end up leaving. (Note 1)

If that is the case, then what propositions should be carried out to improve students' satisfaction with universities, and what kind of environment in the university life could be connected to increasing students' level of satisfaction? In order to get clarity on these matters we will use data from the Meiji Yasuda Institute of Life and Wellness' "University student awareness study" in 2010 (Note 2) to try to analyze the level of satisfaction in university student life. Their survey was designed to cover a wide variety of topics in order to get an understanding of the current university student's lifestyle, behavior, and way of thinking. The target audience for the survey was all of the university students in the nation. The survey samples sizes were divided equally by sex and the student's academic year. The sample size was not corrected to reflect the actual student population distribution in universities.

Many of the previous studies and surveys had pointed out the importance of universities providing higher level of support for the students in form of improving their services and the quality of their classes in order to raise the student's level of satisfaction towards the university student life (Ministry of Education, Culture, Sports, Science and Technology 2000, Benesse Educational Research and Development Institute 2007, Tagawa 2011, etc.). On the other hand, could there be something in the student's own private life, that could is affecting their level of satisfaction towards universities? 
For a student the feeling of satisfaction in their school life and private life is also an important element while they spend time in university. In this research we will combine the results from questions about university and also student's private life to find out if there is a connection between the two in regard to their level of satisfaction. Using the results of the previous studies and surveys mentioned above, and by adding the analysis of the problem in question, we aim to find out what conditions will improve the student life satisfaction level.

\section{Previous Studies}

Many studies have already been conducted on this topic. Most of those studies have been organized by universities themselves to understand their students' level of satisfaction. So what were the results of these studies?

In the analysis of students' level of satisfaction (Tagawa 2011), they gathered information on over 50 topics, which included personal data (sex, age, occupation, place of residence, etc.), human relations inside the campus cafeteria and the university, extracurricular activities, living conditions, etc. From that they concluded that the students who had good relations with their friends in classes and with the faculty members also had a higher level satisfaction. On the other hand, it turned out that the university's name and fame did not affect the level of satisfaction, and if the university's surrounding area was inconvenient, then it would decrease the level of satisfaction. The universities had 3 main reasons for conducting the surveys. First, to understand what students were satisfied with (or dissatisfied with) and if publicly stating that students are satisfied with the university is connected to securing students who wish to enter the university. Second, they wanted to know where the students' dissatisfaction would manifest, so they could boost students' desire to study and decrease the number of students who don't finish university. Third, to get information on how students are treated. In our current age, many students have various needs, and universities consider it extremely important to help satisfy those needs if possible. However, they pointed out that it is difficult to respond to many of the students' needs, which leads to the present situation where students don't graduate, lose interest in studying, etc.

In the Jobu University student satisfaction study's project team in 2013 designed a survey to question the students on their value system, education, facilities and equipment, student life and career support to determine the current situation and their overall satisfaction. At the end of the survey they had a section where students could freely express their opinions. The results showed that satisfaction with education was generally high, and so was overall satisfaction. Facilities and equipment was rated average, but satisfaction with student life and career support was rated below average, which did not include how appropriately paperwork was being handled. Generally speaking the results showed that satisfaction level was high and balanced across all topics. However, the results revealed that many students were dissatisfied with teachers' personalities. Students wished the teachers would warn noisy students, and considered their teaching methods to be bad. As a result of these findings, they proposed active changes in their faculty development program as a means to increase the student satisfaction level.

Nagaoka University conducted a study in 2006 on students's satisfaction towards university, feeling of fulfillment and feeling of accomplishment with their basic goal of giving students a sense of fulfillment through the daily university life, as well as a sense of achievement and overall satisfaction during their four year program. Their results showed that students who were highly satisfied also had high score on their feeling of fulfillment, and if both of those had high ratings then then their sense of achievement was also rated higher. These findings helped them understand that there is a correlation between the sense of satisfaction, fulfillment, and accomplishment. What is more, after asking questions about the students' sense of fulfillment and accomplishment in their lifestyle, relationships, part time jobs, etc. they found out that the students' ultimate sense of satisfaction comes from being able to continue on their chosen path (being able to find work or continue their studies for a master's degree).

From all of these previous studies, we can see that many of the students were not satisfied with the current circumstances and want the university to improve the ease of understanding what is being taught in classes and meet their needs. From the Jobu University and Takawa studies we can also see that improvements in the teaching methods and connected to raising satisfaction in university students.

\section{The Significance of This Study}

In this study we will use the source data from the "University student awareness study (2010)" to look into which factors in the student life affect the student's level of satisfaction. This way we can find out how the different factors affect students' level of satisfaction. Our survey topics included questions about not only things that are directly connected to universities, such as university equipment and classes, but also several questions about the person filling out the survey. These include many questions that were not included in the surveys of the above mentioned previous studies. For example, the student's region of residence, whether or not they are working part time, their parents annual income, etc - things that are not directly connected to the university, but might be indirectly connected. Most of the previous studies focused on the life inside universities. We believe that by adding data of the student's life outside the university we could possibly analyze the student's overall level of satisfaction in life during their time as a student. This 
way we could see if there is a change in students' level of satisfaction with university based on which region they live in, and and we could get a broader understanding of what are the underlying causes for the changes in the level of satisfaction.

The Ministry of Education, Culture, Sports, Science and Technology's study on the absence of school and abandoning university studies before graduating, which was conducted in 2014, reached the conclusion that the biggest reason for quitting or taking time off from studying was due to financial concerns. Aside from that, the main cause for students abandoning their studies was due to poor academic performance, and they also pointed out the possibility that students weren't able to adapt due to the educational gap between high school and university. Poor academic performance leads to lower class attendance. In the survey results from "Investigation into students" class attendance and absence" (Inoue, Shimizu 2002) on the reasons for absence from class, the top two causes for low attendance rates were due to illness or problems relating to poor physical health, and over sleeping due to excessive activities in the previous day that were not connected to studying. From these findings we can assume that something else in the student's life might have higher priority than showing up to class. Continuing this train of thought, if we add together variables from the university life and the students' private life, such as adding the seminar and class attendance rate with whether the student is working part time or not, the number of days spent on extracurricular activities, etc., we can investigate if these variables affect the students level of satisfaction with the university. Understanding that, we could propose what kind of behavior or action is necessary to a student to have a high level of satisfaction with the university life. There are, of course, a number of factors that a student can't change even if they affect the student's satisfaction level with the university life. Such factors include the student's family situation. The reason why we are also taking these variables into consideration is to determine whether or not such indirect things affect the students satisfaction with the university. For example, a student might not be able to change their parents' annual income, but if the income is high, then the student will be able to study without worrying about tuition fees or lecture costs. If students are not forced to work part time, then they can spend that time on studies or on other desirable activities, which will no doubt increase their school life satisfaction level. On the other hand, even if a student's parents' annual income is low, as long as they have a good scholarships, they will have less financial worries like students with students from wealthy families and they will probably also have a higher level of satisfaction with their university life. We believe there are other similar variables that can have a big impact.

\section{Used Data, Variables, Methods, Predictions and Results}

\subsection{Used Data}

The data used in this article originates from the "University student awareness study" that was conducted in 2010 by the Meiji Yasuda Institute of Life and Wellness. Their study was conducted between the 16th and 18th of June 2010, and targeted towards the 1st to 4th year students in both national and private universities in Japan. The sample size was 4120 university students, half of which were male students and the other half were female students, and in total 1030 students per year. The survey focused on questions regarding the level of satisfaction with student life in university, and contained a wide range of questions on the student's sex, region of residence, personal information, whether or not they worked part time, attendance rate in class, whether or not they had friends from the opposite sex, etc. It was an online survey (on the website of Macromill Inc. (Note 3)) so we have no info on the number of valid responses.

At the end of the report we can see the data put together in a chart. In order to analyze the data, we had to convert the results of the survey's topics into numerical values. For example answers to school life satisfaction were divided into: Strongly satisfied, satisfied, indifferent, unsatisfied, strongly unsatisfied. We converted the 5 answers into a 5 point scale, where 1 represents strongly unsatisfied and 5 represents strongly satisfied. The results of the survey showed that 731 students were strongly satisfied, 601 were satisfied, 793 were indifferent, 1757 were unsatisfied, and 238 were strongly unsatisfied, with the highest number of answers being "unsatisfied." Regionally the answers divided as follows: 143 from Hokkaido, 216 from Tohoku, 1913 from Kanto, 557 from Chubu, 771 from Kinki, 176 from Chugoku, 60 from Shikoku, 284 from Kyushu. To make the results easier to analyze, we added the answers from the Kanto and Kinki region together and got 2684 students from urban areas, and 1436 students from the remaining rural areas. (Note 4) Since we felt that the answers were split between too many fields of studies, we decided to group together similar departments and were left with 7 departments, where "Other departments" contained answers from education and sports related departments, which only had a few students.

\subsection{Variables and Methods of Analysis}

In order to find out how the different categories in the surveys affected the level of satisfaction we examined the level of satisfaction with the university (on a 5 point scale) as a dependent variable using multiple regression analysis. (Note 5) All the survey categories are independent variables. The independent variables contain categories from the subjects we were interested in, as well as survey categories from previous studies. The survey results have all been given numerical values like mentioned above with the satisfaction level 5 point scale. Similarly to the "National, public and private 
universities" study's categories, we will use dummy variables (Note 6) when adding numeric rankings is not possible. Chart 1 is the descriptive statistics value (Note 7) of the independent variables that were used in the analysis.

\subsection{Predictions and Results}

Before starting the multiple regression analysis, we would like to set some estimates on which variables we believe might raise or lower the student's university life satisfaction level. We will start with our predictions on which variables might positively affect the satisfaction level. By looking at the previous studies we can assume that things that indicate good personal relations, such as "the existence of relationships with the opposite sex," or "being a member of a club or an association in the university," etc., should raise the level of satisfaction towards university. We also believe that students who are earning money through part time work will have more freedom in what they can spend money on, and give them more options, which should positively affect the satisfaction level. We predict that there are many other variables like students from a high annual income family having a higher level of satisfaction. Apart from that, it is difficult to make predictions on how the student's selected field of study will influence their level of satisfaction. For example, medicine, dentistry, and pharmacy undergraduates will probably have a lower level of satisfaction due to higher tuition fees, longer study period, internship, and generally being busier than undergraduates from other departments. However, we can't presume that all the students in the above fields are in the same situation, and it is thus difficult to predict how their chosen fields will affect their level of satisfaction with the university. It should be reasonable to assume that their level of satisfaction is higher if they themselves made the decision to study in their current field. The level of satisfaction is probably more individual, rather than dependent on which department they are studying in. In addition, students from the same field, but different universities will likely have differences in their level of satisfaction.

The results can be seen in chart 2 . The results show that 12 variables out of the 28 total variables were significant.

Chart 1. Descriptive statistics value

\begin{tabular}{|c|c|c|c|c|}
\hline Variables & Average & $\begin{array}{l}\text { Standard } \\
\text { Deviation }\end{array}$ & Min. Value & Max. Value \\
\hline Sex & 0.500 & 0.500 & 0.000 & 1.000 \\
\hline Region* & 0.651 & 0.477 & 0.000 & 1.000 \\
\hline School year & 2.500 & 1.118 & 1.000 & 4.000 \\
\hline Lodging situation: Living at (parents) home* & 0.551 & 0.497 & 0.000 & 1.000 \\
\hline $\begin{array}{l}\text { Lodging situation: Renting an apartment or other living space } \\
\text { (not living with parents)* }\end{array}$ & 0.405 & 0.491 & 0.000 & 1.000 \\
\hline Lodging situation: Living at the dormitory* & 0.041 & 0.198 & 0.000 & 1.000 \\
\hline University type: National university* & 0.265 & 0.441 & 0.000 & 1.000 \\
\hline University type: Public university* & 0.071 & 0.257 & 0.000 & 1.000 \\
\hline University type: Private university* & 0.664 & 0.473 & 0.000 & 1.000 \\
\hline Department: Science and engineering* & 0.238 & 0.426 & 0.000 & 1.000 \\
\hline Department: Humanities and sociology* & 0.398 & 0.489 & 0.000 & 1.000 \\
\hline Department: Welfare, nursing, healthcare* & 0.047 & 0.211 & 0.000 & 1.000 \\
\hline Department: Medicine, dentistry, and pharmacy* & 0.100 & 0.301 & 0.000 & 1.000 \\
\hline Department: Fine arts* & 0.038 & 0.190 & 0.000 & 1.000 \\
\hline Department: Agriculture, Forestry and Fisheries* & 0.036 & 0.186 & 0.000 & 1.000 \\
\hline Department: Other* & 0.144 & 0.351 & 0.000 & 1.000 \\
\hline Working part time or not* & 0.588 & 0.492 & 0.000 & 1.000 \\
\hline Living parents* & 0.942 & 0.234 & 0.000 & 1.000 \\
\hline Living parents: Only mother* & 0.050 & 0.218 & 0.000 & 1.000 \\
\hline Living parents: Only father* & 0.007 & 0.085 & 0.000 & 1.000 \\
\hline Living parents: No living parents* & 0.001 & 0.031 & 0.000 & 1.000 \\
\hline Parents' annual salary & 2.026 & 1.972 & 0.000 & 7.000 \\
\hline Relationships with the opposite sex* & 0.283 & 0.451 & 0.000 & 1.000 \\
\hline Being a member of a club or an association in the university* & 0.464 & 0.499 & 0.000 & 1.000 \\
\hline University choice was based on desired occupation* & 0.658 & 0.474 & 0.000 & 1.000 \\
\hline Class and seminar attendance rate & 5.045 & 1.709 & 1.000 & 8.000 \\
\hline Self-study at home or at a library & 3.563 & 2.025 & 1.000 & 8.000 \\
\hline Studied in prep school to obtain qualifications & 1.143 & 0.725 & 1.000 & 8.000 \\
\hline Engaged in extracurricular activities & 2.180 & 1.589 & 1.000 & 8.000 \\
\hline Number of days spent working part time & 2.590 & 1.649 & 1.000 & 8.000 \\
\hline Life path after graduating university* & 0.840 & 0.367 & 0.000 & 1.000 \\
\hline University life satisfaction level & 2.959 & 1.230 & 1.000 & 5.000 \\
\hline
\end{tabular}


Explanatory note (1): * Expressed with dummy variables

Source: Data from Meiji Yasuda Institute of Life and Wellness' s "University student awareness study, 2010 “

Chart 2. Affect on student life satisfaction level by each category (Multiple regression analysis)

\begin{tabular}{|c|c|c|c|}
\hline Variables & $\begin{array}{l}\text { Partial Regression } \\
\text { Coefficient }\end{array}$ & Value & $\begin{array}{l}*: \quad \mathrm{P}<0.05 \\
* *: \mathrm{P}<0.01\end{array}$ \\
\hline Sex & -0.108 & 0.005 & $* *$ \\
\hline Region & 0.015 & 0.712 & \\
\hline School year & 0.053 & 0.003 & $* *$ \\
\hline Lodging situation: Living at (parents) home & -0.015 & 0.695 & \\
\hline Lodging situation: Living at the dormitory & -0.069 & 0.453 & \\
\hline University type: National university & 0.969 & $\mathrm{p}<0.001$ & $* *$ \\
\hline University type: Public university & 0.131 & 0.066 & \\
\hline Department: Humanities and sociology & 0.116 & 0.019 & $*$ \\
\hline Department: Welfare, nursing, healthcare & 0.007 & 0.940 & \\
\hline Department: Medicine, dentistry, and pharmacy & 0.006 & 0.927 & \\
\hline Department: Fine arts & 0.265 & 0.010 & $* *$ \\
\hline Department: Agriculture, Forestry and Fisheries & 0.091 & 0.364 & \\
\hline Department: Other & 0.170 & 0.006 & $* *$ \\
\hline Working part time or not & 0.112 & 0.056 & \\
\hline Living parents: Only mother & -0.084 & 0.301 & \\
\hline Living parents: Only father & -0.310 & 0.133 & \\
\hline Living parents: No living parents & -0.118 & 0.834 & \\
\hline Parents' annual salary & -0.007 & 0.415 & \\
\hline Relationships with the opposite sex & 0.134 & $\mathrm{p}<0.001$ & $* *$ \\
\hline Being a member of a club or an association in the university & -0.016 & 0.649 & \\
\hline University choice was based on desired occupation & 0.289 & $\mathrm{p}<0.001$ & $* *$ \\
\hline Class and seminar attendance rate & 0.021 & 0.072 & \\
\hline Self-study at home or at a library & 0.037 & $\mathrm{p}<0.001$ & $* *$ \\
\hline Studied in prep school to obtain qualifications & -0.028 & 0.264 & \\
\hline Engaged in extracurricular activities & 0.072 & $\mathrm{p}<0.001$ & $* *$ \\
\hline Number of days spent working part time & 0.002 & 0.908 & \\
\hline Life path after graduating university & 0.204 & $\mathrm{p}<0.001$ & $* *$ \\
\hline Constant term & 1.724 & $\mathrm{p}<0.001$ & $* *$ \\
\hline
\end{tabular}

Explanatory note (1): * was significant in 5\% of cases, ** was significant in $1 \%$ of cases

Source: Data from Meiji Yasuda Institute of Life and Wellness's “University student awareness study, 2010 “

\section{Examination}

\subsection{The Connection Between the Student Life Satisfaction Level and Various Categories Related to University}

Right from the beginning we understood that a student's academic year positively affected their level of satisfaction with the university life. Meaning that the longer a student had studied in university, the higher their level of satisfaction was. The relationship between a student's academic year and their level of satisfaction has been analyzed in several previous studies (Hamajima 2003, Iwata 2006, etc.), and we could see that their results were consistent. Hamajima suggested that the main reason for it might be whether or not the university where the student is studying was their first choice. Iwata reported that compared to students that were studying in their most desired university, students from a lower grade (first year or second year students) that were not studying in their most desired university had a lower level of satisfaction, but once they reached their 3rd and 4th year in university both their motivation towards school work and student life satisfaction level increased thanks to "relationships with friends" and "lecture quality." So much so that their satisfaction level was not significantly different from that of students that were studying in their most desired university. One more reason why lower grade students rarely gave higher marks for their student life satisfaction level was due to the confusion that arose from transitioning from high school life, where an entire class takes the same courses, to university life, where the student manages their own time and chooses courses based on their own goals (Kimura 2012). (Note 8)

When analyzing changes in the satisfaction level across national, public and private universities, it turned out that compared to private universities being in a national university had a significant positive effect on the student life and on the student' s level of satisfaction. However, being in a public university did not have a significant impact. The reason for national universities being preferred over private universities is probably due to private universities' ${ }^{\prime}$ high tuition fees. According to JASSO's '2014 University Student Life Survey” tuition fees in private universities has become more 
expensive than in national and public universities. They also showed that living costs have become cheapest in private universities, but the total living costs in private universities far exceed that of national universities. There is a study that shows how particularly in economics and other social studies deviation value is a big indicator of the students' level of satisfaction (Shimizu 2013). There are comparatively more national universities with a higher deviation value than private universities, so there is a possibility that students' level of satisfaction is higher there due to having access to better education.

With the exception of "Fine arts" and "Other departments," results show that there are no significant changes to the satisfaction level that arise from a student's chosen field of study. In the predictions section, we wondered whether medicine, dentistry, and pharmacy related studies would affect the satisfaction level. Approximately $92.7 \%$ of the results show that they don't have a significant positive affect on the satisfaction level. In other words, medicine, dentistry, and pharmacy undergraduates do not have a higher level of satisfaction. According to the Benesse report from 2008 , on average university students commuted to university on 4.4 days a week, with about $60 \%$ of students commute to university on 5 or more days a week. Medicine, pharmacy, and healthcare undergraduates had the highest number of days spent on commuting (on average 5 days a week), and $90 \%$ of them spent 5 or more days commuting to school. From this data we can assume that medicine, dentistry, and pharmacy undergraduates had more lectures and a harder student life than students from other departments, and also more mental and physical strain compared to students from departments that had more freedom, which should significantly impact their level of satisfaction.

Thanks to the data from the "Self-study at home or at a library" and "Extracurricular activities" categories, we could see that they had a significant positive effect on their level of satisfaction. These categories show voluntary activities that students themselves decided to do. We can understand that these categories have a significant positive effect on their satisfaction level, because self-motivation and the student's own free will are necessary for voluntary activities. However, "Being a member of a club or an association in the university" category did not have a significant impact on the satisfaction level. This shows that simply being a member of an association is not enough, actually taking part of those activities is important. Simply being a member of an association probably does not affect the satisfaction level. Students that are engaged in extracurricular activities can put effort into those activities, which will help them create fond memories, and find employment in the future. Moreover, they have a higher student life satisfaction level compared to students that don't partake in such activities (Mynavi 2013). This study showed that taking part of extracurricular activities, as opposed to just being an inactive member, probably has a big impact on the student's level of satisfaction.

The results showed that the "Class and seminar attendance rate" category seemed to not have a significant impact. In other words, it is difficult to make the claim that the more a student attends classes and seminars the higher their student life satisfaction level will be. Studies done by Jobu University (2013) and Waseda University (2003) point out that the reason for that is that in the present moment the quality of lectures does not meet students' expectations. (Note 9) One of the reasons could be that the current university students are demanding "lecture's content becoming easier to understand," where they could actually feel that the lectures are becoming easier to understand (Makino 2004). Also, in this article's section 3 part 1, we showed that being an undergraduate from medicine, dentistry, or pharmacy will not have a significant impact on the satisfaction level, but based on the results of both categories we could assume that it might be because they spend more days in a week on commuting.

The results showed that students who answered "already settled" to the "life path after graduating university" category had a significantly higher satisfaction level. If students already had a concrete path after graduation (They had already been promised employment or they had passed the exams to enter master's degree) then their satisfaction level was higher. The reason for that is that students that know what they will do after university will also have a clear idea on what to do in university and thus have an easier time. The 2008 Benesse study results revealed that $65.1 \%$ of university students from their 3rd year and onward are engaged in "Preparations and activities towards life after graduation (including planned activities)." These results can help understand the above mentioned tendency on how a student's level of satisfaction increases as they go up from a first year student to 3rd and 4th year student, as well as see that a correlation might exist between the two variables.

\subsection{The Connection Between a Student's Private Life and Their Level of Satisfaction With University Life}

Results on the satisfaction level difference by sex showed that female students are more satisfied with university life than male students. These results were consistent with that of previous studies like Takawa (2011) and the National Federation of University Co-operative Associations (2015). The latter previous study had divided their results by sex to analyze data on different aspects of student life. The results of that study also pointed out that female students consider lectures more important than male students. In addition, female students also tend to have more experience living abroad and they are more concerned on their future prospects. From these findings we can assume that female students might be having a more meaningful university life. 
No significant differences were noted in the satisfaction level by sorting data based on region (urban and rural). When comparing the level of satisfaction with university life between different regions we used "Transportation accessibility," and "Area around the university," and such categories as a basis for comparison, since they influence the student's perspective and evaluations (Ishii, Okamoto, Kenmochi 2008). Moreover, according to the same study, categories focusing on regional differences seemed to have little impact over how student's choose a university, and it also showed that in the current state the student's interests don't match that of their region. The reason why in this study that category didn't have a significant impact on the level of satisfaction is because, in addition to the variables not including categories related to the university's surrounding area, it is possible that students are not choosing universities based region. Thus they should not affect the level of satisfaction.

As far as the student's living condition go, the data seemed to indicate that students, who were renting living space (outside of their parents' home) or living in dormitories, had a lower level of satisfaction compared to students that lived at home (parents' home), but the results weren't significant. According to JASSO's "2012 University Student Life Survey" reports, students that commute to school from temporary accommodations have much higher student life costs (tuition fees + living expenses) than students that commute to school from home. When taking into consideration the student life costs and other financial concerns, we can assume that students that live in apartments, dormitories or other temporary accommodations have a lower level of satisfaction. Also, the results from 'Study on university students' lifestyle and eating habits based on their living conditions" (Nisho, Ota, Tanaka 2013) revealed that students living with their parents were healthier than students, who were renting living space outside of their parents' home or living in dormitories. Healthy students also rated their own eating habits highly (Maeomiti, Miyoshi, Kashima, Yamasaki, Moriwaki 2014). In addition, because students with healthy eating habits also tend to be more satisfied with university life, it should be plausible that healthiness has a great impact on the student life satisfaction level, equal to that of the financial aspects.

What came out as unexpected from the results of the analysis was that the variables from "Number of days spent working part time" and "Working part time or not" did not have a significant impact on the student life satisfaction level. Also, the variables from "Parents' annual salary" did not match with our estimation that they would have a significant positive affect. There was a previous study (Iwata 2015) that brought up the connection between having a part time job and the student life satisfaction level, but the results from our findings don't match with that previous study. Apart from that, the Waseda University's study "Study on University Student Life" (2007) pointed out that a university's scholarship program's quality is connected to whether or not a student will work part time.

According to that study, if the scholarship program is not sufficient then the students will spend more hours and days working part time. Moreover, the results show that a better scholarship program is clearly connected to the student satisfaction level, as well as closely connected to the university's student life satisfaction level and sense of fulfillment. Unlike part time work, scholarships don't require time and effort. However, part time work takes away free time, and creates mental and physical fatigue. Because of that the students will be unable to focus on university matters, and just like in the above study, "Investigation into students' class attendance and absence" (Inoue, Shimizu 2002), there is a risk of suffering from the same underlying problems. This leads to poor academic performance, and can lead to abandoning studies before graduating. We can surmise that the scholarship program quality has a bigger effect on the student's satisfaction level, as well as their class room attendance rate, compared to whether or not the student has a part time job. (Note 10)

Lastly, we present our observations on "The existence of relationships with the opposite sex."

We assumed that this category should have a significant positive affect on a student's satisfaction level, and this was confirmed by the results. There are only a few previous studies on the connection between this category and university life satisfaction level, but we could see consistent results with the study done by Iwata in 2015. Also, Tagawa's 2013 study that was brought up in "Effect of sense of social stagnation on uninterested to love in adolescent" (Minami 2014) points out that "We can see that romantic relationships create a sense of mental stability, which also impacts their view on relationships with other people." From this we can assume that romantic relations (this also applies to extracurricular activities) develop a person's communication skills and ability to create good relations with other people. We should be able to get consistent results with other previous studies that show that if people have good relationships, then their satisfaction level with their university will also be higher.

\section{Proposals}

The results and analysis made it clear that the following categories were not significant: "Are both parents alive," "Parents' annual salary," "Lodging situation." The first two categories are not something that a student has any control over, and because their results were not significant, along with the latter also not being connected to the satisfaction level, we can conclude that a student's family's circumstances don' affect their student life satisfaction level. In addition, 
we were able to verify that a student's private life and their ability to create good relationships are important factors in leading a meaningful student life with a high level of satisfaction. It is also important for the student to think on what they want to do in the future and if they should go on to study in university. Benesse's "How do high school students choose which university to go to" (2013) results reveal that a large percentage of students don't have a particular occupation they wish to pursue or a field they want to study, and go on to study in university based on their teacher's, friend's or parents' recommendation. The study also points out that such students pessimistically choose a university that they are able to enter with their grades. As mentioned earlier, when students enter university without a plan, hoping to discovering themselves, they will struggle to figure out what to do in university, and they won't be able to focus on lectures, their academic performance will drop, and in the worst case scenario they might abandon their studies. Thus an important element in having a satisfying student life is to probably enter university after getting a clear idea on what they want to do in the future.

However, there are many students that enter university without having a clear idea of their future prospects. Benesse's "Students' thoughts on their future options (2005)" results show that when students were asked why they wish to continue their studies in university, over 50\% of students answered with "Desire to add a university degree to their CV" and "Concerns about finding employment right after high school." 68\% of male students agreed with the first, and 58.7\% agreed with the second answer, while $66 \%$ of female students agreed with the first, and $53.9 \%$ agreed with the second answer. It is difficult to tell everyone to enter university only after figuring out what they want from university. Such students might benefit from taking on different challenges. For example, they could join one of the university's many extracurricular activities. One of the biggest merits of taking part in such activities is gaining new contacts. On top of being part of a group or association, they will be able to polish the skills they will need in the future through cooperation and different challenges. In the Shushoku Journal's study "What did you do in your first and second year of university that was useful when seeking employment?" (2015) brought up extracurricular activities (clubs and circles) as being useful during job hunting. What is more, being a member of a group or an association gives students more opportunities to talk to the opposite sex, as well as form a romantic relationship. In this study, we found out that both taking part in extracurricular activities and having relations with the opposite sex have a significant positive effect on the student life satisfaction level. A student's satisfaction level will improve after entering a club or a circle, and taking part of their activities. These might be a big helping hand for students to lead a meaningful university life.

A university is a place where a student can specialize in a specific field through a higher level of learning than in middle school or high school. On top of that, they can become an important part of society through the voluntary activities and challenges they faced in university. The three most important qualities that companies are looking for when hiring people are independence, communication skills, and the ability to take action (Japan Business Federation 2011). These probably are all skills that students can work on in various clubs or circles, rather than lectures. These skills are what make a person's skill set unique. They also help determine a student's future occupation. If these skills can become a driving force to motivate a student to take actions that will benefit their future, they will have a higher satisfaction level and a more meaningful student life. Whether or not a student will be able to polish those skills is ultimately tied to the student life satisfaction level. This is what we want to conclude from the results of this study.

\section{References}

Internet materials

Asahi, S. K. (2015) Results of Japan University Survey for 2015. http://www.asahi.com/edu/hiraku/article13.html

Benesse Educational Research and Development Institute. (2005) A retrospective study on course decisions. http://berd.benesse.jp/berd/center/open/report/shinrosentaku/2005/houkoku/furikaeri2_1_1.html

Benesse Educational Research and Development Institute. (2008) Survey on university student studies and lifestyle. http://berd.benesse.jp/koutou/research/detail1.php?id=3161

Benesse Educational Research and Development Institute. (2013) How do high school students choose a university? http://berd.benesse.jp/koutou/topics/index2.php?id=2583

JASSO. (2016) 2014 survey on student life. http://www.jasso.go.jp/about/statistics/gakusei_chosa/2014.html

Ministry of Education, Culture, Sports, Science and Technology (2000) Report on measures to improve university student life. http://www.mext.go.jp/b_menu/shingi/chousa/koutou/012/toushin/000601.htm

Mynavi. (2013) Non-participation in extra-curricular activities leads to a drop of 30\% in student life satisfaction. Should extra-curricular activities be made mandatory to ensure fulfilling lives for university students? https://gakumado.mynavi.jp/freshers/articles/11225

National Federation of Student Co-operative Associations. (2015) 2015 university student attitude survey. 
http://www.univcoop.or.jp/press/mind/report-mind2014.html

Shushoku Journal. (2015) What did you do during your first two years in university that was useful when seeking employment? http://journal.rikunabi.com/p/student/souken/17093.html

Waseda University. (2003) Student life report. http://www.waseda.jp/student/research/2003/0311.html

Waseda University. (2007) Survey of student life. http://www.waseda.jp/student/research/2007/07506.html

Yomiuri, S. (2008) "The Power of Universities" survey. http://kyoiku.yomiuri.co.jp/torikumi/jitsuryoku/yomitoku/

Internet PDF materials

Benesse Educational Research and Development Institute. (2007) Student satisfaction levels and university education issues

Hajime Shimizu. (2013) Preliminary analysis on university percentiles and dropout rates; case study of social sciences undergraduate department

Inoue, Shimizu. (2002) Survey on student attitudes toward attendance and absence

Inoue, Shimizu. (2002) Survey on student attitudes toward attendance and absence

Ishii, Okamoto, Kenmochi. (2008) Study on the degree of influence of regional characteristics on a student's choice of university and lifestyle satisfaction

Isobe, Shigematsu. (2007) The reality of university student dietary habits

Iwata. (2015) Factors determining university life satisfaction

Japan Business Federation. (2011) Questionnaire on the candidate profile sought by industry and expectations of university education

JASSO. (2012) Overview of 2012 survey on student life

Jobu University. (2013) Report on the 2013 results analysis of the "Student Satisfaction Survey"

Koji Hamajima, Kozo Iwata. (2005) Analysis of survey of universities and academic years

Kyoko Anegawa. (2014) Analysis of factors in university learning and living environments and university dropout rates

Maeomichi, Ogura, Miyoshi, Kashima, Yamazaki, Moriwaki. (2014) Univerity student self-assessment of dietary habits and the relationships between lifestyle habits, health condition, and dietary habits

Makino. (2004) The influence of evaluation concerns on student evaluation of lessons

Meiji Yasuda Institute of Life and Wellness. (2010) Survey on attitudes concerning university

Minami. (2014) The influence of the sense of social helplessness caused by the "shift away from love" among young people

Ministry of Education, Culture, Sports, Science and Technology. (2014) Report on situations such as school dropout and absence

Nagaoka University. (2006) Report on the 2nd survey on Nagaoka University student life and attitudes toward the university

Nishio, Ota, Tanaka. (2013) Survey on university student diet and lifestyle, based on different types of residential situation

Tagawa. (2003) Exploratory study on the influence of romantic relationships on young people

Takahiro Tagawa. (2011) Analysis of student satisfaction

Takuya Kimura. (2012) Investigation into changes in university satisfaction levels by academic year and their determining factors 


\section{Notes}

Note 1. According to Shimizu (2013) university students are paying tuition fees every year and spending a fixed amount of time on studies to earn credit and to graduate, and if they don't receive an amount of satisfaction that is equal to the university expenses, they will be unsatisfied.

Note 2. Data provided by the Center for Social Research and Data Archives from the Institute of Social Science in the University of Tokyo.

Note 3. Macromill Inc. - Macromill will collect statistical data by having their registered users answer surveys that have been requested by companies and the media, and then provide them the gathered data.

Note 4 . We decided to focus more on the differences between urban and rural areas, rather than analyzing the data by splitting it between eight regions.

Note 5. Multiple regression analysis - method of analysis that tries to explain changes in a certain variable (dependent variable) with 2 or more variables (independent variable, explanatory variable ) that are responsible for the changes.

Note 6. A dummy variable is one that takes the value 0 or 1 to indicate the absence or presence of some categorical effect that may be expected to shift the outcome. For example, changing a survey's answer from "Man" to 1, and "Woman" to 0 . Then by doing a multiple regression analysis, we will be able to identify if there is a difference in the student life satisfaction level between men and women. This statistical method is an important part of multiple regression analysis. Dummy variables are also used in the case of other independent variable.

Note 7. Descriptive statistics value $=$ organized data that has been summarized and placed in a chart or graph to make it easier to read.

Note 8. On the other hand, Kimura emphasizes the contradiction that If the university staff put in effort to create an environment where students can decide their own path and be more active, then as a result students will become more passive and just complacently accept what is presented to them. In other words, the increasing efforts to turn a student into a customer leads to a decline in their proactivity.

Note 9. Inoue, Shimizu (2002) studied what differences exist between students that take lectures seriously (attend classes, finish assignments, etc.) and those that don't. In the study they confirmed that students that take lectures seriously are interested in the lecture, while the other group of students are more concerned about earning credit, and not being allowed to pass a class if they have a certain amount of absences. From these results we can see that presence or absence from classrooms is not relevant, and being able to earn credit from the class is what affects student life satisfaction level.

Note 10. JASSO(2014) also points out that financial support raises the student satisfaction level, which helps relieve several concerns and is connected to leading a fulfilling student life.

\section{Copyrights}

Copyright for this article is retained by the author(s), with first publication rights granted to the journal.

This is an open-access article distributed under the terms and conditions of the Creative Commons Attribution license which permits unrestricted use, distribution, and reproduction in any medium, provided the original work is properly cited. 